\title{
Erratum: Suspension survival mediated by PP2A-STAT3-Col XVII determines tumour initiation and metastasis in cancer stem cells
}

Chen-Chi Liu, Shih-Pei Lin, Han-Shui Hsu, Shung-Haur Yang, Chiu-Hua Lin, Muh-Hwa Yang, Mien-Chie Hung \& Shih-Chieh Hung

Nature Communications 7:11798 doi: 10.1038/ncomms11798 (2016); Published 16 Jun 2016; Updated 22 Dec 2016

This Article contains errors in Figs 4,6 and 7 that were introduced during the production process. In Fig. $4 \mathrm{j}$, the lane labels on the blot should read in order 'Input- No Ab-IgG-Flag'. In Fig. 6i, the $x$ axis label 'WT PP2A' of the two graphs should read 'DN PP2A'. Finally, in Fig. $7 \mathrm{a}$, the maximal cell number reported in the table for the injection of CCS and HT29 should read ' $1 \times 10^{5}$ ' and not ' $1 \times 10^{4}$ '. The correct versions of each figure appear below as Figs 1,2 and 3, respectively. 
a DS727STAT3 $\simeq$ D5 D15
$\beta$-tubulin
$\longrightarrow$

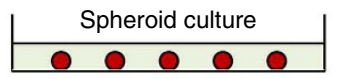

$\rrbracket \mathrm{D} 0,5,15$

Gene expression profile

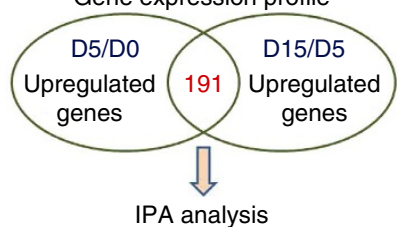

IPA analysis

d

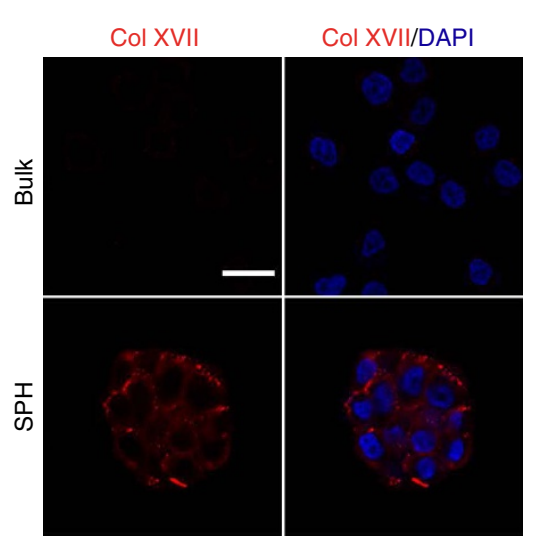

g SPH

ccs CTR si(1) si(2) CTR si(1) si(2)

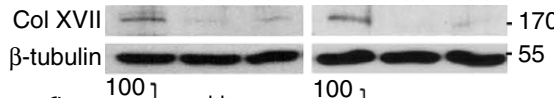

b

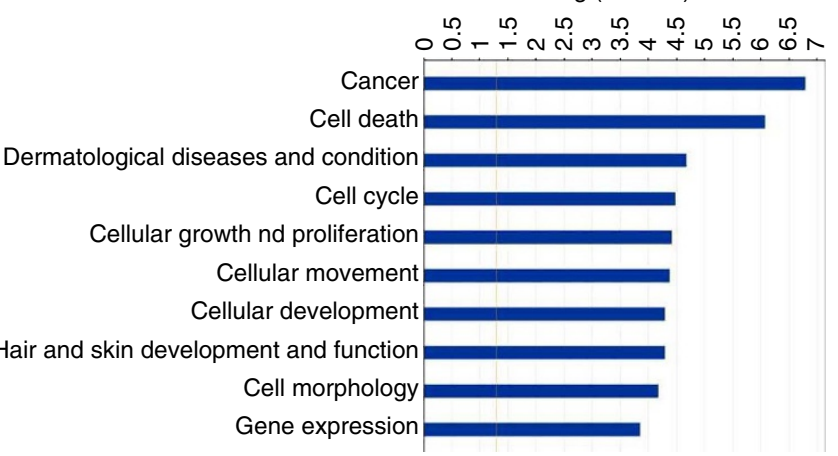

C

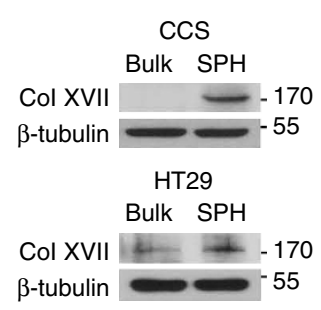

e
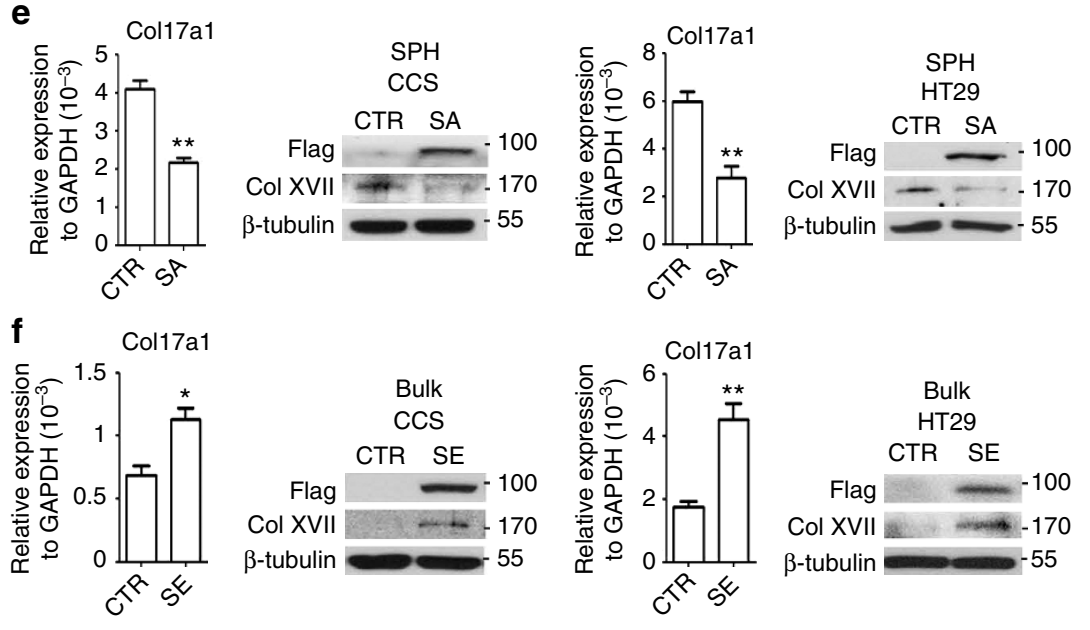

Bulk

HT29

CTR SE

Flag -100

Col XVII $\quad$ wsents -170

$\beta$-tubulin -55

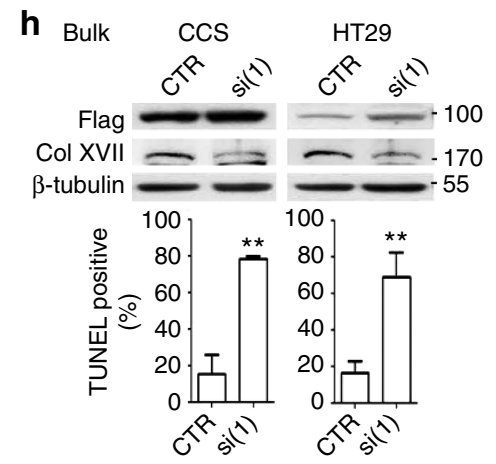

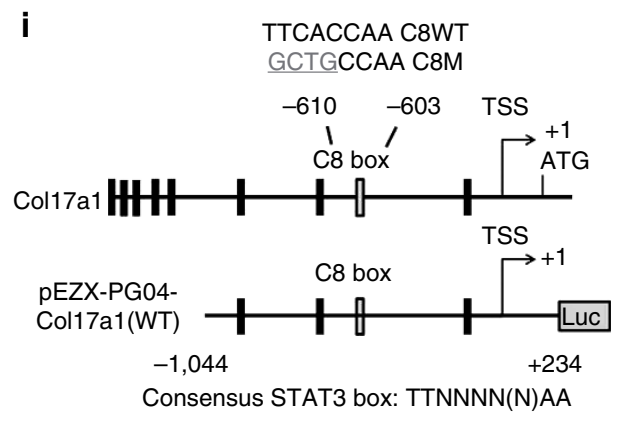

k

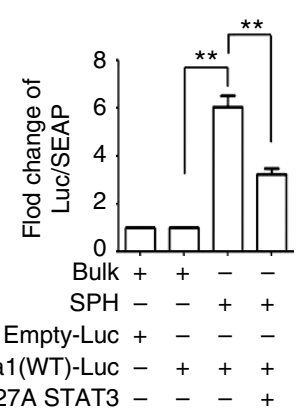

I

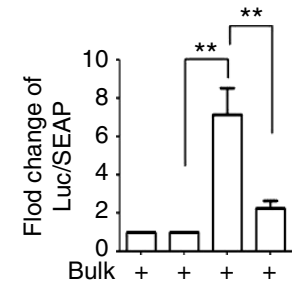

Empty-Luc + - - -

Col17a1(WT)-Luc -++-

Col17a1(C8M)-Luc - $-\quad+$ pFlag-S727E STAT3 - -++

Figure 1 
a

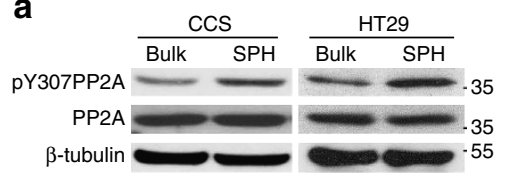

b

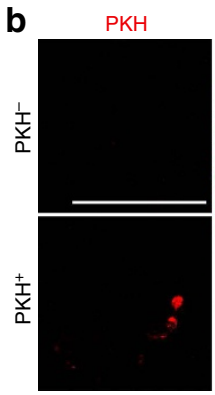

Bulk DMSO Calyculin A (nM)
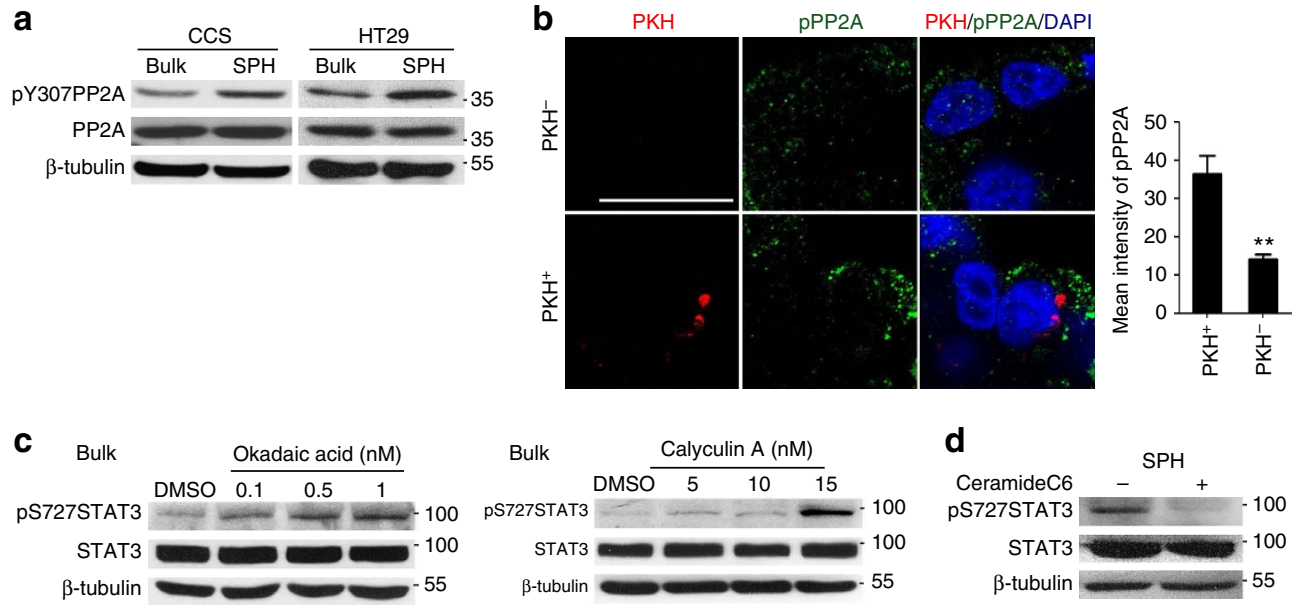

d

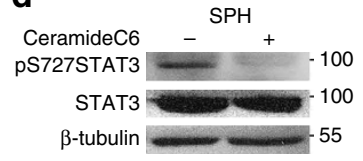

e
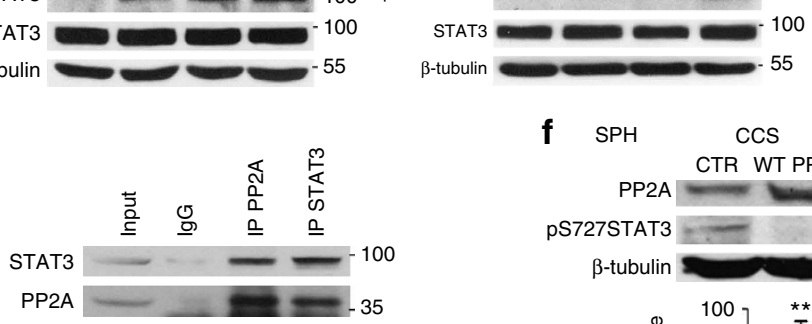

f $\mathrm{SPH} \quad \mathrm{CCS}$ HT29

HT29

PP2A CTR WTP2A CTR WTPP2A

pS727STAT3
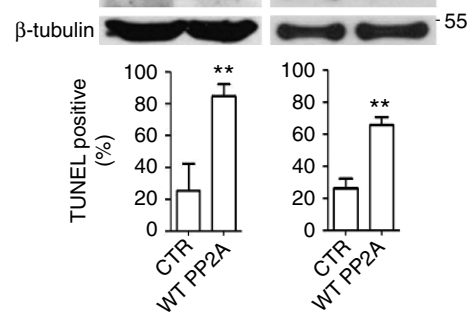

(100)

g

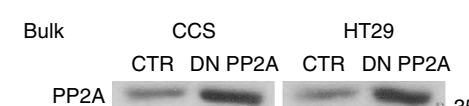

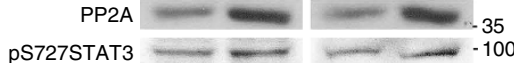

$\beta$-tubulin

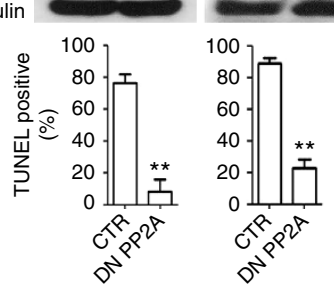

h

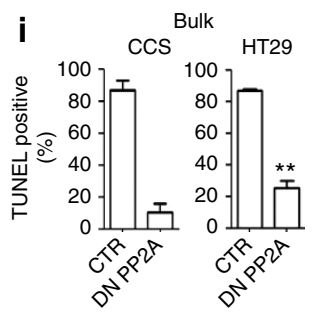

Figure 2 
a

\begin{tabular}{|c|c|c|c|c|}
\hline \multirow[t]{2}{*}{$\operatorname{ccs}$} & \multicolumn{3}{|c|}{ Cell number for injection } & \multirow[b]{2}{*}{$1 \times 10^{5}$} \\
\hline & $10^{4}$ & $2 \times 10^{4}$ & $5 \times 10^{4}$ & \\
\hline CTR (SPH) & & $3 / 4$ & $7 / 8$ & \\
\hline WT PP2A (SPH) & & $0 / 8^{*}$ & $3 / 8$ & \\
\hline CTR (SPH) & & & $7 / 8$ & \\
\hline SA STAT3 (SPH) & & & $0 / 8^{\star *}$ & \\
\hline CTR (SPH) & & & $6 / 8$ & \\
\hline siCol17a1 (SPH) & & & $0 / 8^{* \star}$ & \\
\hline CTR & $0 / 4$ & $0 / 4$ & $0 / 4$ & $0 / 4$ \\
\hline DN PP2A & $0 / 4$ & $1 / 4$ & $2 / 4$ & $4 / 4^{*}$ \\
\hline$\overline{\text { CTR }}$ & $0 / 4$ & $0 / 4$ & $0 / 4$ & $0 / 4$ \\
\hline SE STAT3 & $0 / 4$ & $2 / 4$ & $3 / 4$ & $4 / 4^{*}$ \\
\hline $\mathrm{SE}+$ siCol17a1 & $0 / 4$ & $0 / 4$ & 0/4 & $0 / 4^{*}$ \\
\hline
\end{tabular}

\begin{tabular}{|c|c|c|c|}
\hline \multirow[t]{2}{*}{-ТT29 } & \multicolumn{3}{|c|}{ Cell number for injection } \\
\hline & & $2 \times 10^{4}$ & $1 \times 10^{5}$ \\
\hline \multicolumn{2}{|c|}{ CTR (SPH) } & & $4 / 4$ \\
\hline \multicolumn{2}{|c|}{ CTR (SPH) } & & $4 / 4$ \\
\hline \multicolumn{2}{|c|}{ SA STAT3 (SPH) } & & $0 / 4^{*}$ \\
\hline \multirow{2}{*}{\multicolumn{2}{|c|}{$\begin{array}{l}\text { CTR (SPH) } \\
\text { siCol17a1 (SPH) }\end{array}$}} & & $4 / 4$ \\
\hline & & & $0 / 4^{\star}$ \\
\hline \multirow{2}{*}{\multicolumn{2}{|c|}{ CTR }} & $0 / 4$ & $0 / 8$ \\
\hline DN PP2A & & $0 / 4$ & $6 / 8^{\star *}$ \\
\hline \multicolumn{2}{|l|}{ CTR } & $0 / 4$ & $0 / 4$ \\
\hline \multicolumn{2}{|c|}{ SE STAT3 } & $1 / 4$ & $4 / 4^{\star}$ \\
\hline \multicolumn{2}{|c|}{$\mathrm{SE}+\mathrm{siCol17a1}$} & $0 / 4$ & $0 / 4^{*}$ \\
\hline
\end{tabular}

b
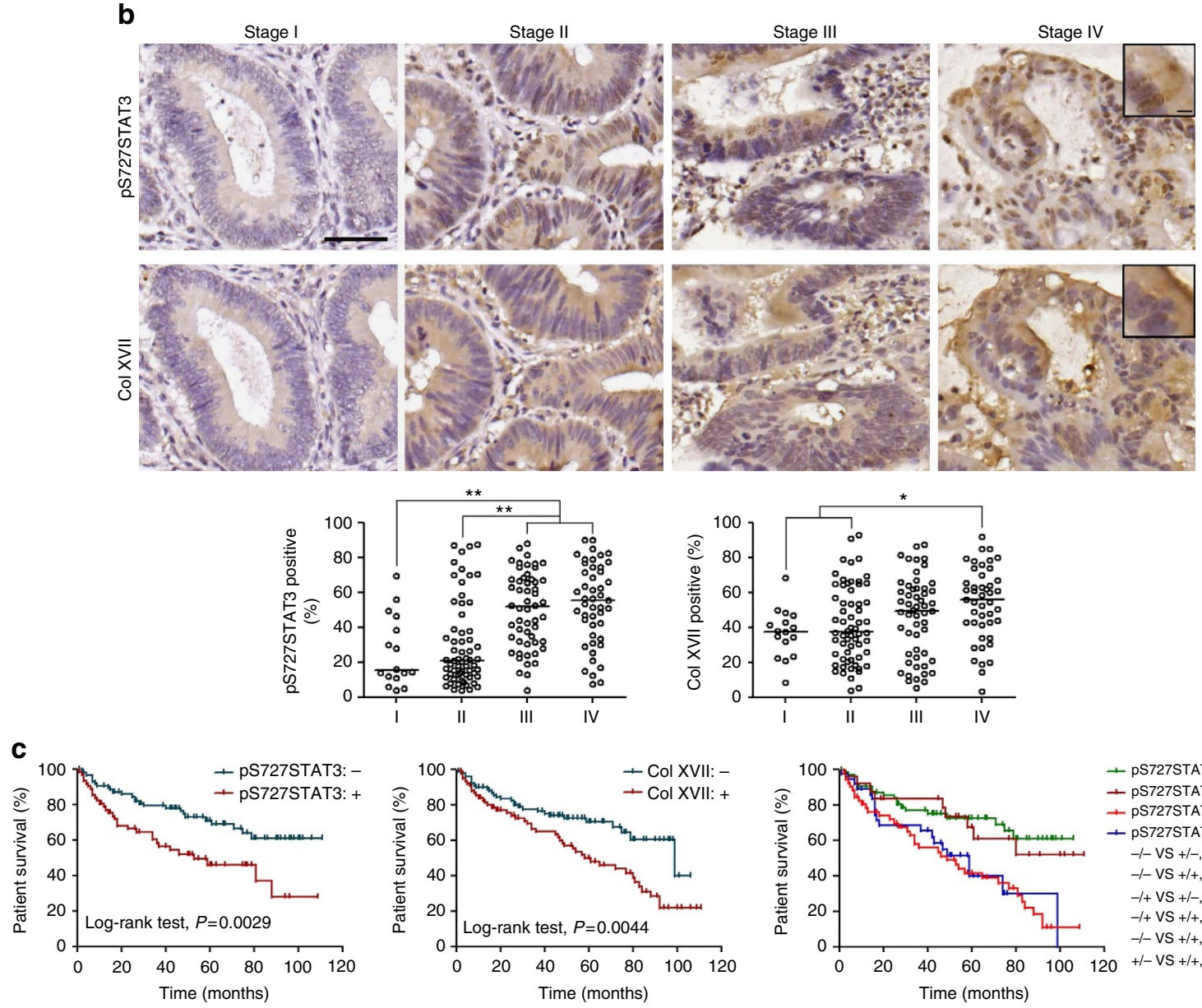

- pS727STAT3/Col XVII: -/- pS727STAT3/Col XVII: -/+ + pS727STAT3/Col XVII: + ++ + pS727STAT3/Col XVII: +/$-/-\mathrm{VS}+/, P=0.0073$ $-/-\mathrm{VS}+/+, P=0.0002$ $-l+\mathrm{VS}+/-, P=0.0403$ $-/+$ VS +/+, $P=0.0107$ $-/-V S+/+, P=0.7058$

Figure 3

(c) (i) This work is licensed under a Creative Commons Attribution 4.0 International License. The images or other third party material in this article are included in the article's Creative Commons license, unless indicated otherwise in the credit line; if the material is not included under the Creative Commons license, users will need to obtain permission from the license holder to reproduce the material. To view a copy of this license, visit http://creativecommons.org/licenses/by/4.0/

(C) The Author(s) 2016 